\title{
ВОЗНИКНОВЕНИЕ И РАЗВИТИЕ ЮРИДИЧЕСКИХ ТЕРМИНОВ В АНГЛИЙСКОМ И АЗЕРБАЙДЖАНСКОМ ЯЗЫКАХ
}

\section{THE ORIGIN AND DEVELOPMENT OF LEGAL TERMS IN ENGLISH AND AZERBAIJANI LANGUAGES}

N. Bayramova

Summary: The article is devoted to the history of the development of legal terms in English and Azerbaijani. The relevance of this article is due to the fact that in studies of various authors only certain aspects of the development of legal terms in these languages are analyzed. This article also gives a brief overview of the most important works on this topic. Since the article is of an overview nature, there is no restriction in the consideration of legal terms to a specific subsystem. The choice of English and Azerbaijani languages for comparing legal terms is determined by the fact that both Great Britain and Azerbaijan are part of the German law group of the Romano-German legal family.

The article describes the works devoted to this problem and also describes the stages of development of legal terms in the English language. According to research calculations of scientists, the core of the legal terminology of the English language is composed of words of old German and Old English origin. Legal terms in English and Azerbaijani languages arose on the basis of commonly used words, which then began to be used as terms in the legal sphere. Since the composition of legal terminology is determined by historical, political, and territorial factors, in the terminology of the languages studied, one can come across terms of a foreign language origin. English and Azerbaijani legal terminology, although they have come a long way, are still in development. In the 21st century, a number of new terms have been formed in the legal terminology of these languages.

Keywords: technical terminology of law, history of the development, borrowing terms, English and Azerbaijan languages.

\author{
Байрамова Нигяр Ашраф гызы \\ Бакинский славянский университет \\ bitkovskayay@inbox.ru
}

Аннотация: Статья посвящена истории развития юридических терминов в английском и азербайджанском языках. Актуальность данной статьи обусловлена тем, что в исследованиях разных авторов анализируются лишь отдельные аспекты развития юридических терминов в указанных языках. В данной же статье дается краткий обзор наиболее важных работ по данной теме. Поскольку статья носит обзорный характер, здесь нет ограничения в рассмотрении юридических терминов до определенной подсистемы. Выбор английского и азербайджанского языков для сопоставления юридических терминов обусловлен тем, что и Великобритания, и Азербайджан входят в группу германского права романо-германской правовой семьи.

По исследовательским подсчетам ученых, ядро юридической терминологии английского языка составляют слова древнегерманского и древнеанглийского происхождения. Юридические термины в английском и азербайджанском языках возникли на основе общеупотребительных слов, которые затем стали употребляться как термины в юридической сфере. Поскольку состав юридической терминологии обусловливается историческими, политическими и территориальными факторами, то в терминологии исследуемых языках можно встретить термины и иноязычного происхождения. Английская и азербайджанская юридическая терминология хоть и прошли длительный путь развития, но все еще находятся в развитии. В XXI веке в юридической терминологии этих языков образовался ряд новых терминов.

Ключевые слова: юридические термины, история развития, заимствованные термины, английские и азербайджанские языки.
$\Pi$ равовая система любой страны неповторима, однако сравнительное правоведение проводит типологию правовых систем посредством их общих и отличительных особенностей. Таким образом формируются типы правовых систем, называемые правовыми семьями. Критериями являются: 1) соотношение и использование источников права, 2) роль суда в создании прецедентов, 3) происхождение и развитие системы права. Выделение правовых семей позволяет ориентироваться в конкретных правовых явлениях, правильно использовать опыт других стран, выявлять и понимать общие тенденции правового развития человечества, обогащать свою правовую и политическую культуру.

Выбор английского и азербайджанского языков для сопоставления юридических терминов обусловлен, вопервых, тем, что и Великобритания, и Азербайджан входят в группу германского права романо-германской правовой семьи. А во-вторых, английский язык имеет статус международного языка, на этом языке развивается международное право, и тем самым, английский язык имеет сильное влияние на развитие любого языка, в том числе и азербайджанского языка (например, посредством заимствований).

Юридическая терминология в английском и азербайджанском языках прошла различные этапы развития, прежде чем достигла современного состояния.

Возникновение и развитие юридических терминов 
в английском языке. История юридической терминологии английского языка насчитывает несколько столетий, уходит своими корнями вглубь веков. Проблеме изучения истории развития английской юридической терминологии посвящено множество научных работ. Например, в работе Е.А. Колядина широко рассматриваются такие проблемы, как:семантическая структура древних англо-саксонских законодательных кодексов; структурно-семантические особенности законов королей Кента и Уэссекса; архитектоника ранних английских законодательных сводов; синтаксические категории древних законодательных текстов (темпоральность, локальность, персональность, модальность и другие) [1].

В исследовании Т.В. Усковой отмечается, что многие юридические термины, употребляющиеся в современном английском языке,отражены в письменных памятникахуже VII века: «manslaughter (непредумышленное убийство), bequlath (завещать), swear (давать показания под присягой), theft (воровство, кража), goods (вещи, имущество), guilt (вина, виновность), land (земля), sheriff (шериф), steal (воровство), thief (вор), murder (убийство), ward (опека)» [5, с. 12].

Поскольку состав терминов уголовного права обусловливается историческими, политическимии территориальными факторами, то здесь можно встретить термины иноязычного происхождения(скандинавского, латинского, французского и древнеанглийского). Однако, по исследовательским подсчетам А. Пыжа, ядро юридической терминологии составляют слова древнегерманского и древнеанглийского происхождения [4, с.10]. Например, из общегерманского языка *aithaz возникло $\rightarrow$ древнеанглийскоеāth $\rightarrow$ современное английское словооаth; из латинского языкаschema (в peзультате утраты флексии) возникло $\rightarrow$ нормандскоесаs $\rightarrow$ современное английское словосаse.

Формирование и история развития английских юридических терминов, точнееэтапы формирования юридической терминологии английского гражданского процессуального права нашли свое отражение в научной работе С.Д. Оськиной [3, с. 3]. В VI-VII веках,в эпоху христианизации Англии в результате вхождения латинского по происхождению слова "leges" в английском языке возник термин "law", выражающий юридическое понятие. Семантика данного термина позднее обогатилась новыми занчениями и оттенками. С.Д. Оськина различает V этапов в возникновении и развитии английской юридической терминологии гражданского процессуального права [3, с. 6-7]:

Кратко охарактеризуем каждый из этапов.

На первом этапе (до 1066 года) на основе юридических обычаев англо-саксонских племен и опыта местных судов возникли следующие термины: witness - свидетель, feudalcourt - суд феодала, will - приказ, воля; lordof county - глава местных судейских органов, bailiff of a village - судебный пристав, бейлиф, управляющий имением, town council - муниципалитет; complaint - недовольство, жалоба, church courts-церковные суды.

На втором этапе (1066-1485 годы) происходит формирование терминов юридической системы. Поскольку в этот период судебные процессы велись на французском языке,то и юридическая терминология обогащается заимствованиями из латинского и французского языков: court - суд,judge - судья, decree - судебное решение, claim - иск, исковое заявление; претензия; притязание, требование; претензия; притязание.

К прямым заимствованиям из латинского языка можно отнести следующие: diploma, consensus, asylum, condominium, territory, ultimatum; юридические термины -“actus reus» (виновное действие; действие, в котором обвиняется подозреваемый в его совершении); corpus delicti (состав преступления); malum inse (по сути своей являющееся преступным действием); производные слова от латинских терминов - demonstrative (доказательный); testament (завещание); testify (свидетельствовать) и другие" [5, с. 13]; а также: diversion (диверсия), codex (законодательный свод), colony (колония), confiscation (конфискация), pretension (претензия/притязание/иск), recidivist (рецидивист), simulation (симуляция), expert (эксперт).

Юридические термины, вошедшие посредством французского языка из латинского: "assault (оскорбление/насилие), crime (преступление), damage (ущерб/ убытки), felony (тяжкое преступление), heir (наследник), larceny (воровство), marriage (брак), misdemeanor (судебно наказуемый проступок, преступление), trespass (нарушение границ частного владения) и другие" [5, с. 13].

В качестве примера для этого периода можем привести “Великая Хартия Вольностей” (1215 год) (lat. Magna Carta Libertatum, ing. The Great Charter). Хартия была составлена на латинском языке, а затем переведена на французский, поскольку французский язык был официальным языком Англии этого периода.На английский язык она была переведена значительно позднее и известна как The Great Charter.

На третьем этапе (1485-1832 годы), по подсчетам С.Д. Оськиной [3, с.6-7], образовались 50\% всех юридических терминов. В этот период также продолжается обогащение терминологической лексики за счет заимствований из латинского и французского языков: judgement - приговор, решение суда, наказание, выговор, proceeding - рассмотрение дела в суде, судебное разбирательство, судопроизводство; јury - присяжные 
заседатели, barrister - адвокат, правозащитник, выступающий в высших судах.

Четвертый этап (охватывает период с 1832 по 1999 годы): С 1863 по 1875годы в связи с реформамив английской судебной системе в юридической терминологии, в том числе и в терминологии гражданского процессуального права расширяется использование терминов образованных синтаксическим способом: divorce courts суды по бракоразводным делам, probate courts - суды по утверждению завещания, actions for damages - суды по возмещению убытков, ущерба.

Пятый этап связан с новыми правилами Гражданского суда вступившими с 1999 года. Происходит замена в употреблении некоторых юридических терминов: термин claimant (истей) заменил использовавшийся ранее термин plaintiff. В настоящее времятермины petitioner (истец) иrespondent (ответчик) используются для обозначения сторон только при обращении в Высший суд по делам семьи. Термин petitioner (истец) вытеснил употреблявшийся ранее в том же значении термин complainant.

Понятно, что английская юридическая терминология хоть и прошла длительный путь развития, но все еще находится в развитии. В XXI векев английской юридической терминологии образовался ряд новых терминов: cyberfraud, domestic partnership, identity theft, racial profiling, alternative minimum tax, three strikes law. Bозникновение данных терминов обусловлено как лингвистическими, так и экстралингвистическими факторами. Е.С. Максименко верно отмечает, что: «Право относится к общественно-политическим наукам и тесно связано с социальной жизнью общества. Юридические термины обладаюти национально-культурным компонентом, поскольку отражают специфику национальной юридической культуры» [2, с. 313].

Лингвистический факторсвязан с постоянным развитием языка, которое не позволяет языку выйти из употребления, а поскольку экстралингвистический фактор связан с обществом, то и происходящие в обществе изменения обязательно отражаются в языке.

Возникновение и развитие юридических терминов в азербайджанском языке. Право возникло вместе с возникновением государства, и поэтому история права также стара, как и история государства. Юридические термины обозначают наименования лиц по профессии, звания и должности, деятельность, событие и процесс, участников этого процесса и т.д.

До XII-XIII веков уже существовали условия для возникновения терминов в азербайджанском языке [7, с. 44]. Это подтверждают и письменные источники азербайджанского языка. Например, “в словаре ИбнМуханна («Китаб хуллийат ул-Инсан ва хулат ул-лисан» («Мастерство языка и его описание») юридические термины носят общественно-политический характер. К ним относятся нижеследующие примеры: sözçӥ (посланник), tünәk (тюрьма), уаğı (враг), хап (правитель), хаqап (правитель), keneş etmə (советовать, указывать дорогу) и так далее" [6, с. 24].

В эпосе "Китаби деде Коркуд" имеется большое количество юридических терминов: divan, tutsaq, sancaq, casus, şəhid, kafər, əmiraxur, təxt, yığnaq və s. Здесь были использованы и юридические термины персидского происхождения divan, düşmәn, zindan, möhür, padşah və s. [11, c. 61-73].

В произведениях азербайджанских классиков юридические термины согласнотребованиям того времени арабского или персидского происхождения. Начиная с XII-XIII веков по XIX векв области права использовались, в основном, термины арабского и персидского происхождения:

В языке Кади Бурханеддин Ахмеда: sərdar, həq, zaman, yigid, dövran və s.

В языке И. Насими: zindan, tanıq (свидетель), әsrük (пьяный), al (хитрость), dövlət, dövran, hәq, hәqiqәt və $\mathrm{s}$.

В языке Хатаи: halal, haram, yolun әуrisi, doğru yol, əmanət, həq, insaf və s.

В языке М. Физули: mülk, tәrki, mal, sultan, şahid, dövr, tələb, bəxt, qərar etmək, hökm, hakim, əmr, qəza, zülm, fəsad, axça, rüşvət, ixtiyar, ixtiyari-bazar, ərz, azad vəs.

В языке М.П. Вагифа: aşkar, etibar, səltənətgah, şah, xunxar, mülk, doğru, halət, ədalət, ədavət, əzab, gizlü, böhtan və s.

B XIX веке в юридической терминологии азербайджанского языка начинают употребляться слова из европейских языков, в том числе и из русского языка. Данное явление было связано с историческими и политическими условиями.

“B XIX веке продолжают употребляться и юридические термины арабско-персидского происхождения: hökm, dövlət, məmləkət, fərman, qərardad, şəhadətnamə, vəkalətnamə, ərizə, qətnamə, icma, sülhnamə və s. Данные термины отличаются последовательным употреблением в произведениях М.Ф. Ахундова, Г. Зардабии других просветителей" [6, с. 28].

Среди юридических терминов того периода отмечаются новые словообразовательные модели слов с исконными корнями и заимствованными суффиксами. По этой причине исследователи оценивают в целом терминологию XIX века как творческий процесс [8, с. 31]. Этот 
факт подтверждают и нижеследующие примеры: әrizəçі, zakonçuluq, silisçi, polisxanə, bizakon və s.

B XIX веке среди источников пополнения юридической терминологии средства официального стиля занимают основное место. Точнее сказать, юридические термины того периода строятся на основе стандартных моделей - синтагм (məsələn, iltizamnamə, vəkalətnamə, әrizənamə, təliqənamə, vəkalətnamə, surəti-fərman, cavabnamə, vəsiyyətnamə, şərtnamə, divanxanə və s.). Как видно, суффиксы персидского происхождения "namə", "хапә" активно участвуют в образовании юридических терминов.

Выше мы уже отметили, что на данном этапе в соответствии с культурно-политическими условиями юридические термины создаются и на основе русского и других европейских языков: senat, qubernator, zakon, prikaz və s.

Всё разнообразие различных по происхождению юридических терминов можно увидеть на страницах газеты XIX века “əkinçi”: şəhadətnamə, icarə, vəkalətnamə, әrizə, mülk, qanun, möhür (арабско-персидского происхождения); prokuror, natarius, karantin, politika, sud, podrat, zakon (заимствованные посредством русского языка из европейских языков). Допускалась и синонимия среди слов, выражающих одинаковое понятие. Например, qanun-zakon, despot-müstəbid və s. В газете "Әkinçi" давались пояснения юридических терминов, а это в свою очередь приводило к параллельности в употреблении терминов. Например, advokat-vəkil: Onların şikvəsinə səbəb...advokatlar, yəni vəkillik edənlər kəslərdir [13, c. 85].

Т. Гаджиев по этому поводу пишет, что «вследствии различия в источниках происхождения и отсутствия органов языкового строительства единый и устойчивый термин для одного и того понятия часто не был определен, появлялась параллельность в употреблении терминов: sud-məhkәтә, zakon-qanun. Вместе с тем, определенная часть заимствований из русского и других европейских языков функционировала в виде словосочетаний. Это, в свою очередь, является "грузом" для языка и, в общем, такое усвоение терминов не приносит пользы: miravoy sud, oqrujnoy sud, qerbavoy (основание), sudebni pristav» ... [8, c. 172-173].

Как было отмечено, в XIX веке юридическая терминология азербайджанского языка обогатилась русизмами. Спустя определенное время данные термины были заменены соответствующими словами из азербайджанского языка. Например, sud, okrujnoy sud, sudu predsedateli, zakon - məhkəmə, hakim, qanun и т.д.

В начале XX века Узеир Гаджибеков в своем словаре, охватывающий частично и юридические термины, дает и их соответствия в нескольких языках (в русском языке, в азербайджанском, арабском и персидском языках). Например, advokat (vəkil), administrator (inzibatçı), aksioner (səhmdar), arest (həbs), divan (məhkəmə), məbus (vəkil), əfvi-ümumi (amnistiya), anarxiya (başsızlıq, iğtişaş), aqitator (təhrikçi), demaqoq (təhrikçi) и т.д. [7].

B начале $X X$ века слова с номинативным значением, типа: tələb, zindan, ixtiyar, buyuruq выходят за рамки бытового употребления и начинают выражать общественно-юридическое значение: ixtiyar (в юридическом значении), tәləb (в политическом, экономическом и юридическом дискурсе в значении «желать»), zindan (плен и тюрьма), buyuruq (официальное указание/постановление) и т.д.

Таким образом, мы пришли в выводу о том, что замена юридических терминов того времени носит формальный характер, поскольку большинство данных терминов были уже ранее освоены с понятийной точки зрения.

В данный период одно и то же юридическое понятие выражается лексико-терминологическими единицами различного происхождения, наблюдается их асистемный повтор. Самой главной особенностью остается различное происхождение юридической терминологии. Например, konflikt - münaqişə, Dövlət Duması - Dövlət Şurası, amnistiya - əfvi-ümumi, münafiqlik - provakasiya, təhlil - analiz и т.д.

Юридические термины, употребляясь в судебных документах, создают специфику содержания отдельных постановлений и статей. Судебные документы представляют собой юридическую область функционирования официально-делового стиля. В статье, приведенной из "Уголовно-процессуального кодекса Азербайджанской Республики" ("Передача подсудимого общественным организациям или трудовым коллективам для его перевоспитания и исправления" (статья 5) такие слова и словосочетания, как: vəsatət, prokuror, müstəntiq, cinayət işi, xitam etmək, cinayət etmiş şəxs, islah olunmaq, zaminə vermək, təqsirli şəxs, məhkəmə, təqsirli hesab etmə, icraat являются терминами, употребляющимися в судебной практике. Можно продолжить этот ряд примеров: kassasiya, instansiya, iddiaçı, iclasçı, cavabdeh, müsadirə, həbs, dindirmə, götürmə [12, c. 192-193].

"Употребляющиеся в современной юридической прессе термины характеризуются новизной содержания и формы. Например, transfer, qanunvericilik, azadlıq, nizam, qaydalar, - monopoliya, ictimai sektor, özəl sektor, suverenlik və s." [9, c. 328].

\section{Схожие черты -}

1) на возникновение и развитие юридических 
терминов в обоих языках повлияли как лингвистические, так и экстралингвистические факторы,

2) юридические термины обоих языков образуют постоянно развивающуюся систему (поскольку весь язык находится в развитии); система юридической терминологии характеризуется новизной содержания и формы,

3) структура и содержание юридических терминов в обоих языках характеризуется тенденцией к унификации и исконности по происхождению; отличительные черты -

1) юридические термины английского языка более компрессивны по сравнению с азербайджанским;

2) в юридической терминологии английского языка имеются устойчивые заимствованные словосочетания или варваризмы.

\section{ЛИТЕРАТУРА}

1. Колядин Е.А. Древнеанглийский законодательный свод как тип текста: Автореф. дисс. . .. канд. фил.наук. Нижний Новгород, 2012, 23 с.

2. Максименко Е.С. Национально-культурная специфика номинации универсальных правовых концептов, создающих научную картину мира, в английской и американской юридической терминологии // Языки профессиональной коммуникации: Материалы международной научной конференции / Отв. ред. Е.И. Голованова. Челябинск, 2003, с. 313-316.

3. Оськина С.Д. Актуальные проблемы развития и современного состояния английской терминологии гражданского процессуального права. Автореферат диссертации на соискание ученой степени кандидата филологических наук. Омск, 2007, 23 с.

4. Пыж А.М. Функционально-прагматические и дискурсивные аспекты использования английской юридической терминологии. Автореф. дисс. ... канд. фил.наук. Сам. гос. пед. ун-т., Самара, 2005, 21с.

5. Ускова Т.В. Когнитивно-дискурсивные особенности англоязычной юридической терминологии. Автореф. дисс. ... канд. фил.наук. М.: 2008, 25с.

6. Allahverdiyeva G. Türk və Azərbaycan dillərində hüquq terminologiyasının formalaşması və inkişafı. Fil. ü. fəl. dok. ... diss. B., 2005, 143s.

7. Hacıbəyov Ü. Mətbuatda müstəməl siyasi, hüquqi, iqtisadi və əsgəri sözlərin türk- rusi və rusi-türk lüğəti. Bakı, 1907.

8. Hacıyev T.i. Azərbaycan ədəbi dili tarixi (II hissə). "Maarif", Bakı, 1987, 293 s.

9. Hüquq, qanunvericilik və azadlıq. Cild 3, F. A.Hayek. Bakı, Qanun, 2002.

10. Qasımov M.Ş. Azərbaycan dili terminologiyasının əsasları. Bakı, Elm,1973, $186 \mathrm{~s}$.

11. Piriyev E. "Kitabi-Dədə Qorqud" dastanlarında fars sözlərinin işlənmə tezliyi. // Türk Dillərinin yazılı abidələrinə dair tədqiqlər. Azərbaycan Dövlət Universiteti, Bakı, 1985.

12. Salehova I. Məhkəmə sənədləri rəsmi işgüzar üslubun fəaliyyət sahələrindən biri kimi. //Tədqiqlər 2. Bakı, 2000, s. 192-197.

13. "Okinçi" qəzeti, 23 avqust, 1996, №16, s. 85.

(c) Байрамова Нигяр Ашраф гызы (bitkovskayay@inbox.ru). 